\title{
Isolation, Identification and Pharmacological Activities of Endophytic Fungi from Aponogeton undulatus Roxb.
}

\author{
Nargis Sultana Chowdhury ${ }^{1 *}$, Farhana Farjana ${ }^{1}$, Md. Hossain Sohrab ${ }^{2}$ \\ ${ }^{1}$ Manarat International University, Dhaka, Bangladesh \\ ${ }^{2}$ Pharmaceutical Sciences Research Division (PSRD), BCSIR Laboratories, Dhaka, Bangladesh \\ Email: *nscmiu@gmail.com, ^nargis@manarat.ac.bd, Farhanafarjana5@gmail.com, mhsohrab@yahoo.com
}

How to cite this paper: Chowdhury, N.S., Farjana, F. and Sohrab, Md.H. (2020) Isolation, Identification and Pharmacological Activities of Endophytic Fungi from Aponogeton undulatus Roxb. Pharmacology \& Pharmacy, 11, 350-361.

https://doi.org/10.4236/pp.2020.1112028

Received: November 5, 2020

Accepted: December 13, 2020

Published: December 16, 2020

Copyright $\odot 2020$ by author(s) and Scientific Research Publishing Inc. This work is licensed under the Creative Commons Attribution International License (CC BY 4.0).

http://creativecommons.org/licenses/by/4.0/

\begin{abstract}
The objective of this study is to isolate, identify and investigate the pharmacological activities of the endophytic fungi from an aquatic plant Aponogeton undulatus Roxb. ( $A$. undulatus). Endophytic fungi were isolated and identified based on morphological characters. The molecular identification of the fungal isolates was performed using by analyzing the DNA sequence based on mega BLAST program. Spectrums of antibacterial and antifungal activities were studied by Agar diffusion methods. Extracts of the endophytic fungal strains isolated from the plant $A$. undulatus were screened for probable cytotoxic activities using brine shrimp lethality bioassay. Six endophytic fungi, namely AULE-1, AULE-2, AULE-3, AURE-1, AURE-3 and AURE-4 were isolated and purified from the leaves and roots of the plant such as strains AULE-1 as Trichooderma sp., AULE-2 as Carvularia sp. AULE-3 as Penicillium sp. strains AURE-1 and AURE-4 as Fusarium sp. and AURE-3 as Mucor sp. Strain AURE-4 was further identified as Fusarium solani. At $300 \mu \mathrm{g} / \mathrm{disc}$ concentration, six ethyl acetate extracts of endophytic fungi of the plant $A$. undulates showed moderate to significant activities against most of the test bacteria and pathogenic fungi. The strain AURE-4 exhibited strong cytotoxic activities $(10.18 \mu \mathrm{g} / \mathrm{mL})$ compared to the standard antitumor agent vincristine sulphate and this positive result suggests that fungal extracts may contain antitumor or pesticidal compounds. This is the first study to report the isolation, identification, antimicrobial and cytotoxic properties of endophytic fungi of Aponogeton undulatus Roxb. in Bangladesh.
\end{abstract}

\section{Keywords}

Endophytic Fungi, Aponogeton undulatus, Fusarium solani, Antibacterial Activity, Cytotoxic Activity 


\section{Introduction}

Bangladesh possesses a rich flora of aquatic plants. Aquatic plants in wetlands carry out photosynthesis as primary producers in the ecosystem, with blooms at the surfaces of freshwater. Therefore, aquatic plants are considered useful resources because of their ability to purify water [1] [2] [3]. Aquatic plants or hydrophytes are highly adapted to their environment with unique morphological and physiological features [4] and these features are likely to make the aquatic plants unique habitats for the growth of potentially distinctive endophytic fungi. Endophytic fungi are ubiquitously found in the internal tissues of all plant species [5]. Despite the cryptic nature of their symbiotic existence in host plants, they have gained recognition as prolific producers of secondary metabolites that have potential in medical and agricultural applications useful to mankind [6]. However, much of the Earth's endophytic fungal population, estimated to be in the millions, remains uninvestigated [7]. Compared to their terrestrial counterparts endophytic fungi of aquatic plants are far less investigated with respect to secondary metabolite production and their biological activities [8] [9]. The plant growth promoting activity and the induction of systemic resistance (ISR) by these fungi in their host plants has been widely researched [10] [11] [12] [13] [14]. There are so many plants of Bangladesh which are untouched for investigation of their biological activity [15]. Aquatic genus Aponogeton is represented by approximately 57 species all over the world [16]. Aponogeton undulatus Roxb. ( $A$. undulatus), commonly called Green bulb tree belongs to the family Aponogetonaceae and occurs in India, Sri Lanka, Myanmar, Bangladesh and China [17]. The plant is claimed to be effective against cough, tuberculosis, acne, cancer, diarrhoea, dysentery, jaundice etc. [18]. A. undulatus also possess remarkable antitumor activity [19]. The endophytic fungi of Apnogeton undulatus or their bioactive metabolites have not been investigated earlier. So the purpose of this present study is to provide the information about the isolation, identification and bioactive potential of endophytic fungi from leaves and roots of that plant $A p$ nogeton undulatus.

\section{Materials and Methods}

The aquatic plants Aponogeton undulatus Roxb. were collected from Chalan Beel area (24.52N, 89.01E), Natore, Bangladesh during the rainy season (July) of 2017 (Figure 1). They were identified by Bangladesh National Herbarium, Dhaka, Bangladesh. A voucher specimen (DACB: 32072) has been deposited in the Herbarium for further reference. Healthy (showing no visual disease symptom) and mature plants were carefully chosen for sampling. Leaves and roots from different sites of the plant were randomly collected for the study. The plant material was brought to the laboratory in sterile bags and processed within a few hours after sampling. Fresh plant materials were used for isolation work to reduce the chance of contamination [20].

About 300 grams of fresh and healthy parts of the plant (leaves and roots) 


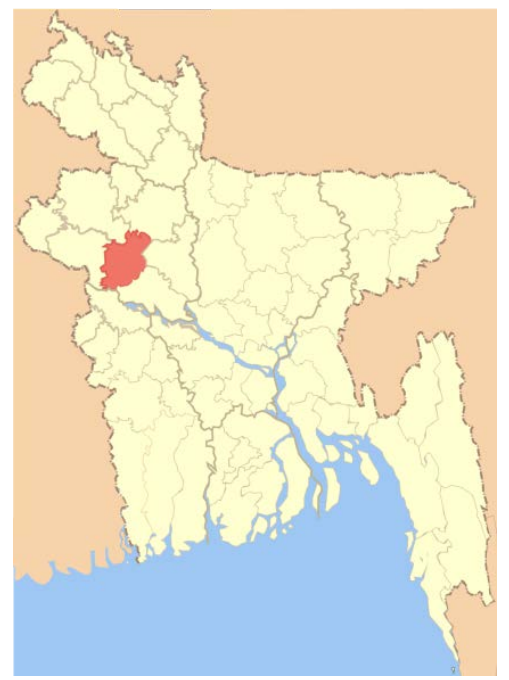

(a)

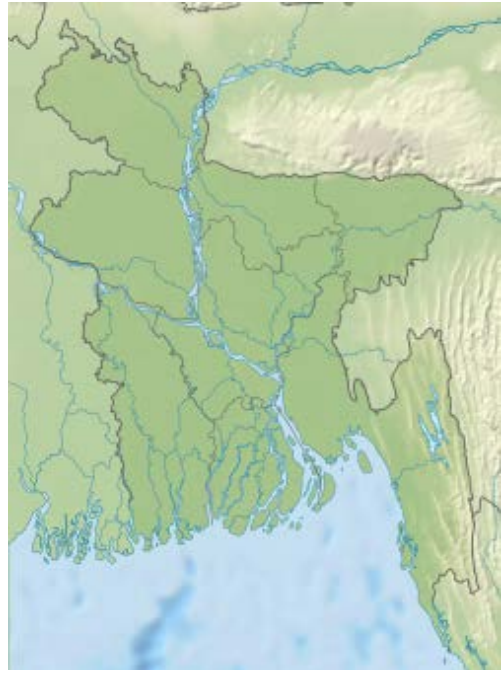

(b)

Figure 1. Location of Natore in Bangladesh (a); Location of ChalanBeel at Natore in Bangladesh (b).

were cut with a sterile scalpel and stored at $4^{\circ} \mathrm{C}$ in a sterile polythene bag prior to use. Endophytic fungi were isolated from the fresh plant parts following the procedure, suitably modified [21].

\subsection{Morphological Identification of Fungal Cultures}

For the identification of endophytic fungal isolates, slides prepared from cultures were stained with lactophenol cotton blue reagent and examined with a brightfield and phase contrast microscope [22]. Identification was based on morphological characteristics such as growth pattern, hyphae, the color of the colony and medium, surface texture, margin character, aerial mycelium, sporulation and production of acervuli, coloration of the medium, and the size and coloration of the conidia using standard identification manuals [23]. The fungi were identified using relevant keys and taxonomic notes from various standard manuals [24] [25].

\subsection{DNA Extraction, PCR Amplification and Sequencing}

The identification of the fungal isolates was mainly performed using molecular characterization by analyzing the DNA sequence of the ITS region of the ribosomal RNA gene. Each fungus sample was cultured in potato dextrose agar (PDA) at room temperature. Mycelium of the fungus was filtered and the isolation of genomic DNA from the mycelia of each fungal isolate was carried out using DNA isolation kit for genomic DNA (Maxwell 16, Promega, USA) according to the published protocol [26] [27]. The ITS region of the isolated genomic DNA was amplified by polymerase chain reaction (PCR) using the forward primer ITS 1 (5'TCCGTAGGTGAACCTGCGG3') and the reverse primer ITS 4 (5'TCCTCCGCTTATTGATATGC3') under the conditions, initial denaturation of $5 \mathrm{~min}$ at $94^{\circ} \mathrm{C}$, followed by 35 cycles of $30 \mathrm{sec}$ at $94^{\circ} \mathrm{C}, 1 \mathrm{~min}$ at $55^{\circ} \mathrm{C}$ and $2 \mathrm{~min}$ 
at $72^{\circ} \mathrm{C}$, with a final extension of $7 \mathrm{~min}$ at $72^{\circ} \mathrm{C}$ [28]. The amplified DNA was sequenced commercially and was BLAST analysed [National Center for Biotechnology Information (NCBI)]. The acquired gene sequences were submitted to the NCBI GenBank database and accession number (KY511422) was obtained. The fungal voucher specimens were preserved on PDA slants at $4^{\circ} \mathrm{C}$ at the Pharmaceutical Sciences Research Division, BCSIR Laboratories, Dhaka, Bangladesh.

\subsection{Extraction of the Culture Medium}

The six endophytic fungal strains were cultivated on a small scale at $28^{\circ} \mathrm{C}$ for 28 days in potato dextrose agar (PDA) medium. At the end of stationary phase of culture, fermented medium was filtered using three layers of muslin cloth to remove the mycelia. The resulting culture filtrate was extracted thrice with ethyl acetate. Then, the solvent phase was reduced under pressure using rotary vacuum evaporator (Heidolph, Germany) [20].

\subsection{Antimicrobial Assay}

Spectrums of antibacterial and antifungal activities were studied by using the technique described by Bauer [29]. Kanamycin and Ketoconazole sensitivity disc (30 $\mu \mathrm{g} /$ disc) were used as a positive control for bacteria and fungi, respectively. Solvents are used as negative control. The zones of growth inhibition around the discs were measured after 18 to $24 \mathrm{hrs}$ of incubation at $37^{\circ} \mathrm{C}$ for bacteria and 48 to $96 \mathrm{hrs}$ of incubation at $28^{\circ} \mathrm{C}$ for fungi. The sensitivities of the microorganism species to the fungal extract $(100 \mu \mathrm{g} / \mathrm{disc})$ were determined by measuring the diameter of inhibitory zones in millimeter. The test microorganisms used in the antimicrobial study included four pathogenic bacterial strains Staphylococcus aureus ATCC 25923, Escherichia coli ATCC 28739, Bacillus megaterium ATCC 18 and Pseudomonas aeruginosa ATCC 27833, two fungal strains Aspergillus niger and $A$. flavus. All the cultures were obtained from ICDDR,B. The bacterial cultures were sub-cultured every two weeks on fresh nutrient agar (NA) slants and incubated at $37^{\circ} \mathrm{C}$ whereas the fungal cultures were sub-cultured every four weeks on the fresh potato dextrose agar (PDA) slants and incubated at $28^{\circ} \mathrm{C}$.

\subsection{Brine Shrimp Lethality Bioassay}

Brine shrimp lethality bioassay was conducted to evaluate cytotoxicity of the fungal extracts. For the experiment, $4 \mathrm{mg}$ of each of the endophytic fungal extracts was dissolved in dimethylsulfoxide (DMSO) and solutions of varying concentrations $(400,200,100,50,25,12.5,6.25,3.13,1.56,0.78 \mu \mathrm{g} / \mathrm{ml})$ were obtained by the serial dilution technique using simulated seawater. The solutions were then added to the pre-marked vials containing 10 live brine shrimp nauplii in $5 \mathrm{ml}$ simulated seawater. After $24 \mathrm{~h}$, the vials were inspected using a magnifying glass and the number of survived nauplii in each vial was counted [30]. The mortality endpoint of this bioassay was defined as the absence of controlled for- 
ward motion during $30 \mathrm{~s}$ of observation. From this data, the percent of lethality of the brine shrimp nauplii for each concentration and control was calculated. An approximate linear correlation was observed when logarithm of concentration versus percentage of mortality was plotted on the graph paper and the values of $\mathrm{LC}_{50}$ were calculated using Microsoft Excel 2003. Vincristine sulphate was used as the reference cytotoxic drug [31].

\subsection{Statistical Analysis}

A statistical analysis was used to interpret the antimicrobial and cytotoxic results. The experiment was conducted in completely randomized design with 3 replicates. The results are presented as means \pm standard error of means using MS excel [32].

\section{Result and Discussion}

\subsection{Morphological Identification of Fungal Cultures}

Isolation, purification and cultivation of endophytic fungi have been done following the published method [33], suitably modified. A total of six endophytic fungi, namely AULE-1, AULE-2, AULE-3, AURE-1, AURE-3 and AURE-4 were isolated and purified from the leaves and roots of the plant Aponogeton undulatus Roxb. They exhibited characteristic colony and microscopic morphology that could be used to differentiate them. Fungi were identified taxonomically to the genus level on the basis of macroscopic and microscopic morphological characters in culture medium (Figure 2). Six (6) endophytic fungi, are identified such as strains AULE-1 as Trichooderma sp., strains AULE-2 as Carvularia sp., strains AULE-3 as Penicillium sp., strains AURE-1 and AURE-4 as Fusarium sp. and AURE-3 as Mucor sp.

The microscopic characters of strain AULE-I showed mycellium hyaline, pale or brightly colored branched and septate, conidiohores are arising from the mycelium singly or less often in synnemata, branched near the apex, ending in phialides, spores brightly colored mass, one celled, ovoid, in dry basipetal chain. These characteristics indicated that the fungus AULE-I belongs to Trichoderma sp. Strain AULE-2 showed profusely branched, septate and hyaline mycellium, conidophores are grey and simple, bearing spore apically, conidia dark, end cell lighter, typically bent, with one of the central cell enlarged. These morphological characteristics indicated the fungus AULE-2 belongs to Curvularia sp. Strain AULE-3 exhibited mycellium hyaline, pale or brightly colored branched and septate, conidiohores are arising from the mycellium singly or less often in synnemata, branched near the apex, ending in phialides, spores brightly colored mass, one celled, ovoid, in dry basipetal chain. These morphological characteristics indicated the fungus AULE-3 belongs to Penicillium sp. Strain AURE-1 was identified as Fusarium sp. It exhibited cottony mycelium, conidia or phialospores hyaline, two kinds of spores are observed. Macroconidia were several celled, slightly curved or bent at the pointed end. Microconidia were one celled, 


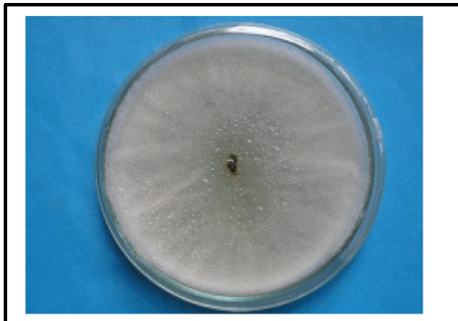

AULE-1

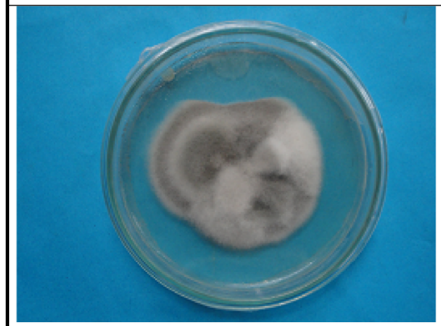

AULE-2

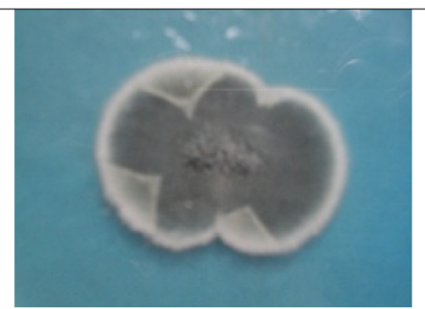

AULE-3

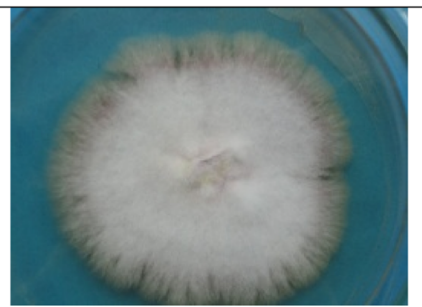

AURE-1

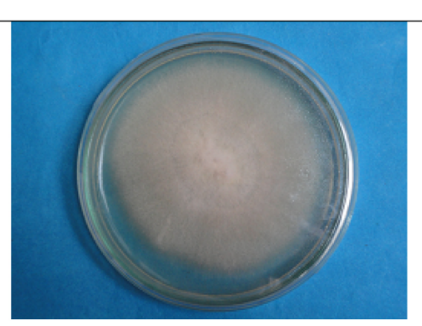

AURE-3

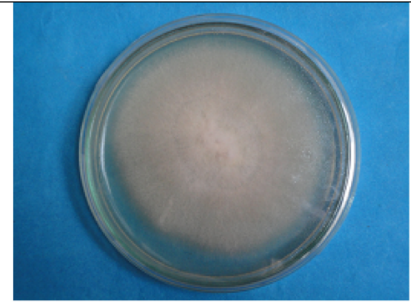

AURE-4

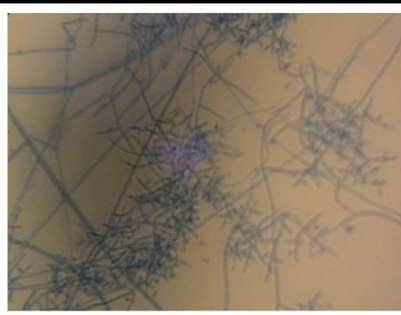

AULE-1 (Microscopic view)

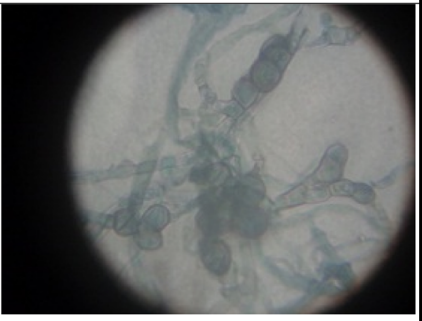

AULE-2 (Microscopic view)

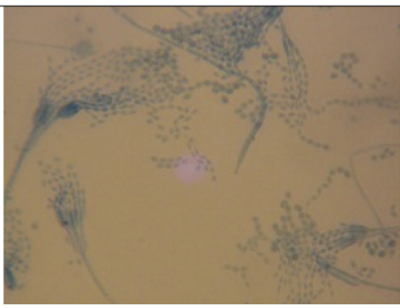

AULE-3(Microscopic view)

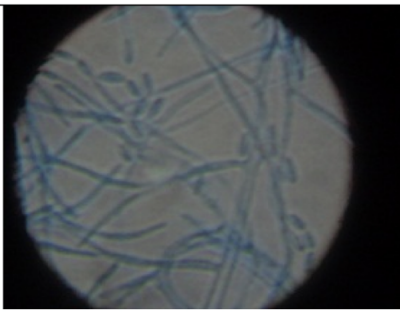

AURE-1(Microscopic view)

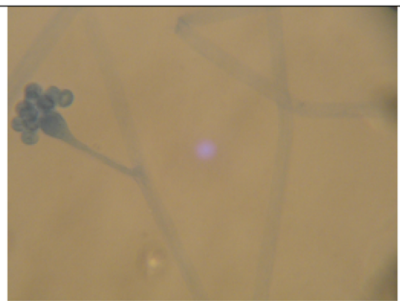

AURE-3(Microscopic view)

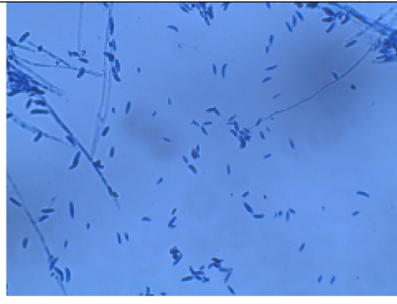

AURE-4(Microscopic view)

Figure 2. Macroscopic and microscopic (100x) colony morphologies of the endophytic fungi from Aponogeton undulatus Roxb. 
oblong, borne singly or in chain, colony was fluffy, spores cylindrical, septate and aseptate. In case of AURE-3, the mycelium consists of white grey cottony muchbranched mycelium, rapid growth. The hyphae are prostrate, conidiospore producing globose sporangia on sporangiophores those are either solitary or branched. Rhizoids and stolons are absent. These characteristics indicated that the fungus AURE-3 belongs to Mucor species. Strain AURE-4 was identified as Fusarium sp. The mycelia profusely branched and septate, colony was fluffy white colored. Conidiospores produced macroconidialseptation from 3 to 5 , sparse to abundant cottony mycelium with white-creamy to white-reddish colour of aerial mycelium and the pigmentations were reddish brown with a dark brown zonation. The feature of conidiogenous cell with branched and long monophialides were commonly observed.

\subsection{Molecular Identification of the Endophytic Fungus AURE-4 as Fusarium solani}

One of the endophytic fungus (AURE-4) from the plant Aponogeton undulatus was grown on PDA for 28 days at $28^{\circ} \mathrm{C}$ and morphologically characterized. The mycelium was scraped directly from the surface of the agar culture (5 days old) and weighed. Nucleic acid was extracted and purified using the DNA isolation kit for genomic DNA (Maxwell 16, Promega, USA) using the manufacturer protocol. For identification and differentiation, the Internal Transcript Spacer regions (ITS4 and ITS5) and the intervening 5.8S rRNA region was amplified and sequenced using electrophoretic sequencing on an ABI $3730 \times 1$ DNA analyzer (Applied Biosystems, USA) using Big Dye Terminator v 3.1 cycle sequencing kit.

The PCR product was purified using $2 \%$ Agarose-Gel-Electrophoresis at $75 \mathrm{~V}$ for 60 minutes in TBE buffer. The agarose gel was then stained using 1\% ethidium bromide. A $100 \mathrm{bp}$ stained DNA fragment was then excised from the agarose gel. The next step of PCR product purification was performed using Gel Cleanup Kit. The binding buffer was mixed to the PCR product and incubated at $50^{\circ} \mathrm{C}$ for 10 minutes at $1000 \mathrm{rpm}$. The mixture was mixed with a volume of isopropanol and then centrifuged. The filtrate was discarded and the column was washed with wash buffer twice followed by centrifugation. Amplified fungal DNA (PCR product), which was incorporated into the column, was eluted by addition of elution buffer or molecular biology grade water to the center of the column. The column was then centrifuged to collect the filtrate, which was the fungal DNA dissolved in elution buffer. The amplified fungal DNA was then submitted for sequencing by a commercial service and the base sequence was compared with publicly available databases such as GenBank with the help of Blast-Algorithmus. Finally, the sequence data (ESI) was deposited to Genbank database (accession number KY511422). The sequence data revealed 99\% similarity to another fungal isolate of accession number KC764913.1 that has shown 99\% similarity with Fusarium solani (accession numbers KM235740.1, KJ207395.1, KJ719812.1, FJ719812.1, EU625403.1, KU382502.1 etc.) deposited in the US Na- 
tional Center for Biotechnology Information (NCBI).

\subsection{Antimicrobial Screening of Endophytic Fungi from A. undulatus}

Six ethyl acetate extracts of endophytic fungi (Strains AULE-1, AULE-2, AULE3, AURE-1, AURE-3 and AURE-4) of the plant $A$. undulatus showed moderate to significant activities against most of the test bacteria and pathogenic fungi (Table 1). The zone of inhibition were produced by the fungal extracts were found to be $11-36 \mathrm{~mm}$ at a concentration of $300 \mu \mathrm{g} / \mathrm{disc}$. Extracts of the strains AURE-4 and AULE- 1 were found to be more active compare to the other extracts. Extract of the strain AURE-4 was found to be exhibiting promising activities against Escherichia coli $(28.55 \pm 0.35 \mathrm{~mm})$, Staphylococcus aureus $(25.54 \pm$ $0.75 \mathrm{~mm})$, Pseudomonas aeruginosa $(25.51 \pm 0.65 \mathrm{~mm}$ ) and Bacillus megaterium $(24.50 \pm 0.45 \mathrm{~mm})$.Extract of the strain AULE-1 was found to show prominent activities against Escherichia coli (30.52 $\pm 0.65 \mathrm{~mm})$, Pseudomonas aeruginosa $(24.55 \pm 0.25 \mathrm{~mm})$, Staphylococcus aureus $(25.54 \pm 0.75 \mathrm{~mm})$ and moderate activities against Bacillus megaterium $(22.50 \pm 0.45 \mathrm{~mm})$. Interestingly the crude extract of the strain AURE-4 exhibited potent antifungal activities against $A s$ pergillus niger $(36.45 \pm 0.55 \mathrm{~mm}$ ) and Aspergillus flavus $(33.65 \pm 0.35 \mathrm{~mm})$. The extracts of the strains AURE-4 and AULE- 1 are very promising. This positive result suggests that all of the fungal extracts may contain metabolites with antimicrobial potency. This is the first report of antimicrobial activities of endophytic fungi from an aquatic plant Aponogeton undulatus Roxb.

\subsection{Brine Shrimp Lethality Bioassay of Endophytic Fungi of A. undulatus Roxb.}

Extracts of the endophytic fungal strains isolated from the plant $A$. undulatus were screened for probable cytotoxic activities using brine shrimp lethality bioassay. The $\mathrm{LC}_{50}$ value of the extracts of the strains AULE-1, AULE-2, AULE-3,

Table 1. Antimicrobial activity of the endophytic fungal extracts isolated from Aponogeton undulatus Roxb.

\begin{tabular}{|c|c|c|c|c|c|c|c|}
\hline \multirow{2}{*}{$\begin{array}{c}\text { Test } \\
\text { Microorganism }\end{array}$} & \multicolumn{6}{|c|}{$\begin{array}{l}\text { Diameter of the inhibition zone }(\mathrm{mm}) \\
\text { Crude extracts }(300 \mu \mathrm{g} / \mathrm{disc})\end{array}$} & \multirow{2}{*}{$\begin{array}{c}\text { Standard } \\
\text { Antibiotic/ } \\
\text { Antifungal }\end{array}$} \\
\hline & AURE-1 & AURE-3 & AURE-4 & AULE-1 & AULE-2 & AULE-3 & \\
\hline B. megaterium & $14.50 \pm 0.45$ & $14.50 \pm 0.55$ & $24.50 \pm 0.45$ & $22.50 \pm 0.45$ & $14.52 \pm 0.65$ & $10.54 \pm 0.75$ & $31.35 \pm 0.95$ \\
\hline$S$. aureus & $15.54 \pm 0.75$ & --- & $25.54 \pm 0.75$ & $23.54 \pm 0.75$ & $15.52 \pm 0.65$ & $13.55 \pm 0.25$ & $32.52 \pm 0.65$ \\
\hline$P$. aeruginosa & $25.51 \pm 0.55$ & $12.52 \pm 0.65$ & $25.51 \pm 0.65$ & $24.55 \pm 0.25$ & $17.55 \pm 0.25$ & $12.50 \pm 0.45$ & $31.35 \pm 0.35$ \\
\hline E. coli & $20.55 \pm 0.25$ & $15.55 \pm 0.35$ & $28.55 \pm 0.35$ & $30.52 \pm 0.65$ & $17.50 \pm 0.45$ & $13.54 \pm 0.75$ & $30.37 \pm 0.73$ \\
\hline A. niger & --- & $25.45 \pm 0.55$ & $36.45 \pm 0.55$ & --- & --- & --- & $41.52 \pm 0.94$ \\
\hline A. flavus & --- & --- & $33.65 \pm 0.35$ & --- & --- & --- & $48.56 \pm 0.45$ \\
\hline
\end{tabular}

Note: The diameter of zone of inhibition are expressed as mean \pm SD. $(n=3)$; a diameter less than 8 mm was considered inactive. Zone of inhibition (mm) determined after $24 \mathrm{~h}$ of incubation at $37^{\circ} \mathrm{C}$. 


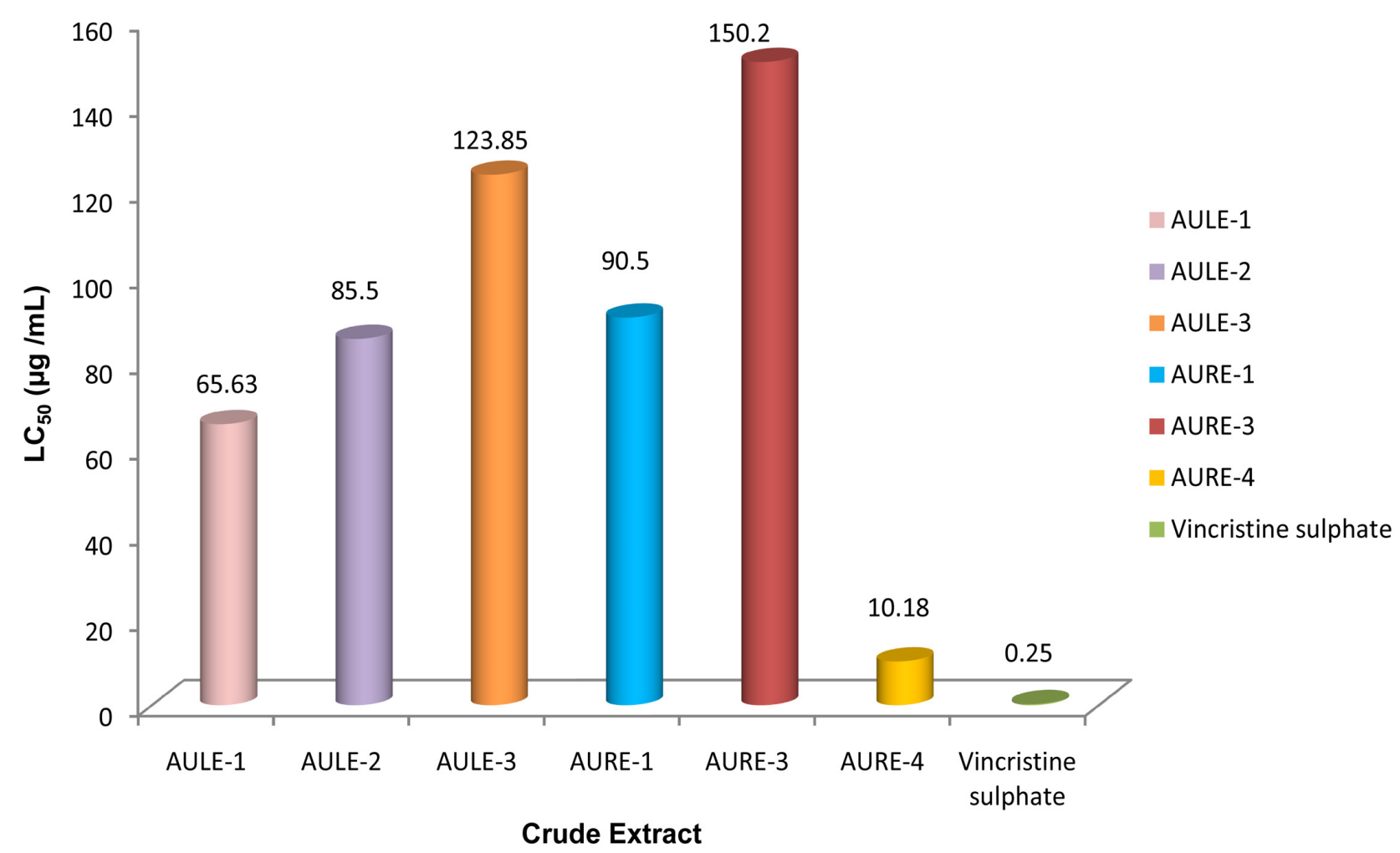

Figure 3. Effect of plant and different fungal extracts of $A$. undulatus on brine shrimp nauplii.

AURE-1, AURE-3 and AURE-4 were found to be $65.63 \mu \mathrm{g} / \mathrm{mL}, 85.50 \mu \mathrm{g} / \mathrm{mL}$, $123.85 \mu \mathrm{g} / \mathrm{mL}, 90.50 \mu \mathrm{g} / \mathrm{mL}, 150.20 \mu \mathrm{g} / \mathrm{mL}$ and $10.18 \mu \mathrm{g} / \mathrm{mL}$, respectively (Figure 3) compared to the standard antitumor agent vincristine sulphate $\left(\mathrm{LC}_{50}\right.$ value $0.25 \mu \mathrm{g} / \mathrm{mL}$ ). It is evident that most of the test samples were lethal to brine shrimp nauplii. All the fungal extracts showed low $\mathrm{LC}_{50}$ values and thus demonstrated their quite potent cytotoxic activities. However, extract of the fungal strain AURE-4 was comparatively more active with minimum $\mathrm{LC}_{50}$ values and the strain AURE-3 was less active with maximum $\mathrm{LC}_{50}$ value. The strain AURE-4 exhibited strong cytotoxic activities and this positive result suggests that fungal extracts may contain antitumor or pesticidal compounds. This is also the first report of cytotoxic activities of endophytic fungi from an aquatic plant Aponogeton undulatus Roxb. However, this cannot be confirmed without further higher and specific tests.

\section{Conclusion}

This is the first study to isolate the endophytic fungi of the native aquatic plant Aponogeton undulatus Roxb. and investigation of their biological activities. This study showed that the aquatic plant Aponogeton undulatus Roxb. harbours many endophytic fungi that are capable of producing antimicrobial as well as cytotoxic substances. The results presented here support the notion of an ecology basedapproach to selection of fungal species for chemical studies, as this demonstrates that such an approach can be effective in the discovery of new bioactive fungal 
metabolites. Thus it can be concluded that the endophytic fungi of Aponogeton undulatus Roxb. may be a potential source for the isolation of bioactive metabolites and more investigations should be performed to realize its true potential.

\section{Acknowledgements}

The authors are thankful to the authority of BCSIR for supporting the work in this paper through a fellowship to NSC and also for providing the lab facilities related to the work on endophytic fungi.

\section{Conflicts of Interest}

The authors declare no conflicts of interest regarding the publication of this paper.

\section{References}

[1] Carpenter, S.R. and Lodge, D.M. (1986) Effects of Submersed Macrophytes on Ecosystem Processes. Aquatic Botany, 26, 341-370.

https://doi.org/10.1016/0304-3770(86)90031-8

[2] Desmet, N.J., van Belleghem, S., Seuntjens, P., Bouma, T.J., Buis, K. and Meire, P. (2011) Quantification of the Impact of Macrophytes on Oxygen Dynamics and Nitrogen Retention in a Vegetated Lowland River. Physics and Chemistry of the Earth, 36, 479-489. https://doi.org/10.1016/j.pce.2008.06.002

[3] Yeh, T.Y., Ke, T.Y. and Lin, Y.L. (2011) Algal Growth Control within Natural Water Purification Systems: Macrophyte Light Shading Effects. Water, Air, \& Soil Pollution, 214, 575-586. https://doi.org/10.1007/s11270-010-0447-4

[4] Yakandawala, D. (2012) Present Status of Fresh Water Aquatic Flora in Sri Lanka. In: Weerakoon, K. and Wjesundera, S., Eds., The National Red List 2012 of Sri Lanka; Conservation Status of the Fauna and Flora, Ministry of Environment, Colombo, 186-196.

[5] Strobel, G. and Daisy, B. (2003) Bioprospecting for Microbial Endophytes and Their Natural Products. Microbiology and Molecular Biology Reviews, 67, 491-502. https://doi.org/10.1128/MMBR.67.4.491-502.2003

[6] Aly, A.H., Debbab, A. and Proksch, P. (2011) Fungal Endophytes: Unique Plant Inhabitants with Great Promises. Applied Microbiology and Biotechnology, 90, 1829 1845. https://doi.org/10.1007/s00253-011-3270-y

[7] Colwell, R.R. (2002) Fulfilling the Promise of Biotechnology. Biotechnology Advances, 20, 215-228. https://doi.org/10.1016/S0734-9750(02)00011-3

[8] Shearer, C.A., Descals, E., Kohlmeyer, B., Kohlmeyer, J., Marvanova, L., Padgett, D., Porter, D., Raja, H.A., Schmit, J.P. and Thorton, H.A. (2007) Fungal Biodiversity in Aquatic Habitats. Biodiversity and Conservation, 16, 49-67. https://doi.org/10.1007/s10531-006-9120-Z

[9] Wang, L., Dong, Song, H., Shen, K.Z., Wang, L.M., Sun, R., Wang, C.R., Li, G., Li, L. and Zhang, K.Q. (2008) Screening and Isolation of Antibacterial Activities of the Fermentative Extracts of Freshwater Fungi from Yunnan Province, China. Annals of Microbiology, 58, 579-584. https://doi.org/10.1007/BF03175561

[10] Redman, R.S., Sheehan, K.B., Stout, R., Rodriguez, R.J. and Henson, J.M. (2002) Thermotolerance Generated by Plant/Fungal Symbiosis. Science, 29, 1581. 
https://doi.org/10.1126/science.1072191

[11] Waller, F., Achatz, B., Baltruschat, H., Fodor, J., Becker, K., Fischer, M., Heier, T., Hückelhoven, R., Neumann, C. and von Wettstein, D. (2005) The Endophytic Fungus Piriformospora indica Reprograms Barley to Salt-Stress Tolerance, Disease Resistance, and Higher Yield. Proceedings of the National Academy of Sciences of the United States of America, 102, 13386-13391.

https://doi.org/10.1073/pnas.0504423102

[12] You, Y.H., Yoon, H., Kang, S.M., Shin, J.H., Choo, Y.S., Lee, I.J., Lee, J.M. and Kim, J.G. (2012) Fungal Diversity and Plant Growth Promotion of Endophytic Fungi from Six Halophytes in Suncheon Bay. Journal of Microbiolog and Biotechnology, 22, 1549-1556. https://doi.org/10.4014/jmb.1205.05010

[13] You, Y.H., Yoon, H., Kang, S.M., Woo, J.R., Choo, Y.S., Lee, I., Shin, J.H. and Kim, J.G. (2013) Cadophoramalorum Cs-8-1 as a New Fungal Strain Producing Gibberellins Isolated from Calystegiasoldanella. Journal of Basic Microbiology, 53, 630-634. https://doi.org/10.1002/jobm.201200002

[14] You, Y.H., Kwak, T.W., Kang, S.M., Lee, M.C. and Kim, J.G. (2015) Aspergillus clavatus Y2H0002 as a New Endophytic Fungal Strain Producing Gibberellins Isolated from Nymphoides peltata in Fresh Water. Mycobiology, 3, 87-91.

https://doi.org/10.5941/MYCO.2015.43.1.87

[15] Chong, K., Tan, H.T., Corlett, W. and Richard, T. (2009) A Checklist of the Total Vascular Plant Flora of Singapore: Native, Naturalised and Cultivated Species. Raffles Museum of Biodiversity Research, National University of Singapore, Singapore, 273.

[16] Chen, L.Y., Grimm, W.G., Wang, Q.F. and Renner, S.S. (2015) A Phylogeny and Biogeographic Analysis for the Cape-Pondweed Family Aponogetonaceae [Alismatales]. Molecular Phylogenetics and Evolution, 2, 111-117. https://doi.org/10.1016/j.ympev.2014.10.007

[17] Watson, L. and Dallwitz, M.J. (1992) Aponogetonaceae, the Families of Flowering Plants.

[18] Biswas, S.K. and Ghosh, S.E. (1977) Bharotio Bonoushadhi. Calcutta University Press, Calcutta.

[19] Islam, M.R., Alam, M.B., Tamima, U. and Jenny, S.I. (2015) Antitumor Activity of Aponogeton undulatus against Ehrlich Ascites Carcinoma in Swiss Albino Mice. Asian Pacific Journal of Tropical Medicine, 8, 431-437. https://doi.org/10.1016/j.apjtm.2015.05.010

[20] Alzoreky, N.S. and Nakahara, K. (2003) Antibacterial Activity of Extracts from Some Edible Plants Commonly Consumed in Asia. International Journal of Food Microbiology, 80, 223-230. https://doi.org/10.1016/S0168-1605(02)00169-1

[21] Kusari, S., Lamschöft, M., Zühlke, S. and Spiteller, M. (2014) Endophytes Are Hidden Producers of Maytansine in Putterlickia Roots. Journal of Natural Products, 77, 2577-2584. https://doi.org/10.1021/np500219a

[22] Sadananda, T.S., Govindappa, M. and Ramachandra, Y.L. (2014) In Vitro Antioxidant Activity of Lectin from Different Endophytic Fungi of Viscum album L. British Journal of Pharmaceutical Research, 4, 626-643. https://doi.org/10.9734/BJPR/2014/6702

[23] Devi, N.N. and Prabakaran, J.J. (2014) Bioactive Metabolites from an Endophytic Fungus Penicillium sp. Isolated from Centella asiatica. Current Research in Environmental \& Applied Mycology, 4, 34-43. https://doi.org/10.5943/cream/4/1/3

[24] Barnett, H.L. and Hunter, B.B. (1998) Illustrated Genera of Imperfect Fungi. APS 
Press, St. Paul.

[25] Dugan, F.M. (2006) The Identification of Fungi: An Illustrated Introduction with Keys, Glossary and Guide to Literature. American Phytopathological Society, Saint Paul.

[26] Crouch, J.A., Clarke, B.B. and Hillman, B.I. (2005) Phylogenetic Relationships and Fungicide Sensitivities of Colletotrichum graminicola Isolates from Turfgrass in North America. International Turfgrass Society Research Journal, 10, 186-195.

[27] White, T.J., Bruns, T., Lee, S. and Taylo, J.L. (1990) Amplification and Direct Sequencing of Fungal Ribosomal RNA Genes for Phylogenetics. In: Innis, M.A., Gelfnad, D.H., Sninsky, J.J. and White, T.J., Eds., PCR Protocols. A Guide to Methods and Applications, Academic Press, San Diego, 315-322.

https://doi.org/10.1016/B978-0-12-372180-8.50042-1

[28] Diaz, P.L., Hennell, J.R. and Sucher, N.J. (2012) Genomic DNA Extraction and Barcoding of Endophytic Fungi. In: Sucher, N.J., Hennell, J.R. and Carles, M.C., Eds., Plant DNA Fingerprinting and Barcoding. Methods and Protocols, Methods in Molecular Biology, Springer Science + Business Media, Berlin, 171-179. https://doi.org/10.1007/978-1-61779-609-8_14

[29] Bauer, A.W., Kirby, W.M.M., Sherris, J.C. and Turck, M. (1966) Antibiotic Susceptibility Testing by a Standardized Single Disk Method. American Journal of Clinical Pathology, 45, 493-496. https://doi.org/10.1093/ajcp/45.4_ts.493

[30] Meyer, B.N., Ferrigni, N.R., Putnam, J.E., Jacobsen, L.B., Nichols, D.E. and McLaughlin, J.L. (1982) Brine Shrimp: A Convenient General Bioassay for Active Plant Constituents. Planta Medica, 45, 31-34. https://doi.org/10.1055/s-2007-971236

[31] Mirand, E.A. and Murphy, G.P. (1983) LNCaP Model of Human Prostatic Carcinoma. Cancer Research, 43, 1809-1818.

[32] Ansar, M. and Gulam, M. (2018) Phenolic Contents, Antimicrobial and Antioxidant Activity of Olea ferruginea Royle (Oleaceae). BMC Complementary and Alternative Medicine, 18, 173. https://doi.org/10.1186/s12906-018-2239-0

[33] Kusari, P., Kusari, S., Spiteller, M. and Kayser, O. (2013) Endophytic Fungi Harbored in Cannabis sativa L.: Diversity and Potential as Biocontrol Agents against Host Plant-Specific Phytopathogens. Fungal Diversity, 60, 137-151. https://doi.org/10.1007/s13225-012-0216-3 